\title{
Stabilization of Expansive Soils Using Mechanical and Chemical Methods: A Comprehensive Review
}

\author{
Armand Augustin Fondjo ${ }^{1, *}$, Elizabeth Theron ${ }^{1}$, Richard P Ray ${ }^{2}$ \\ ${ }^{1}$ Department of Civil Engineering, Central University of Technology, South Africa \\ ${ }^{2}$ Department of Structural and Geotechnical Engineering, Széchenyi István Egyetem University, Hungary
}

Received March 19, 2021; Revised April 29, 2021; Accepted June 6, 2021

\section{Cite This Paper in the following Citation Styles}

(a): [1] Armand Augustin Fondjo, Elizabeth Theron, Richard P Ray, "Stabilization of Expansive Soils Using Mechanical and Chemical Methods: A Comprehensive Review," Civil Engineering and Architecture, Vol. 9, No. 5, pp. 1295 - 1308, 2021. DOI: 10.13189/cea.2021.090503.

(b): Armand Augustin Fondjo, Elizabeth Theron, Richard P Ray (2021). Stabilization of Expansive Soils Using Mechanical and Chemical Methods: A Comprehensive Review. Civil Engineering and Architecture, 9(5), 1295 - 1308. DOI: 10.13189/cea.2021.090503.

Copyright $\bigcirc 2021$ by authors, all rights reserved. Authors agree that this article remains permanently open access under the terms of the Creative Commons Attribution License 4.0 International License

\begin{abstract}
The presence of expansive soils on construction sites is problematic in geotechnical engineering. The swell-shrink behaviour makes these soils not suitable to be used in their natural state. The expansive soil damages cause financial loss yearly more than floods, hurricanes, tornadoes, and earthquakes combined. Moreover, the cost of cut to spoil of expansive soils during construction projects has continued to rise because of the high cost of earthworks, haulage, and the increasing scarcity of spoil areas because of the built environment. Nonetheless, a proper stabilization technique can significantly enhance the expansive soil's properties. The research project attempts to review, report the limits and merits of mechanical and chemical methods utilized to stabilize expansive soils in line with their efficiency, environmental concerns, and cost-effectiveness. A review of mechanical and chemical treatment techniques is conducted in this regard. Ultimately, each stabilization method exhibits its merits and limitations. The lack of standards for the treatment of swelling soils is a significant problem in engineering practice. Specialists in the domain of soil treatment must work together to obtain an optimized stabilization approach and protocol. Moreover, engineers should perform a geoenvironmental assessment appropriate for chemical stabilization methods and additives utilized. This research work contributes as a guideline in the selection and application of chemical and mechanical stabilization methods.
\end{abstract}

Keywords Expansive Soils, Soil Stabilization,
Mechanical Methods, Chemical Methods, Additives

\section{Introduction}

Expansive soils (ES) present significant structural and geotechnical challenges worldwide. The soil deformations (swell/shrink) induce significant defects in Lightweight constructions [1,2]. Lightweight constructions generally exhibit damages when subjected to ES movement. Reference [3] pointed out that the defects related to ES are not a result of the absence of engineering solutions, but the failure to diagnose the presence and intensity of swell/shrink of these soils in the early stage of the project. Countries that reported the ES damages include South Africa, Morocco, Mexico, Israel, Spain, Turkey, Iran, India, Great Britain, Ethiopia, Ghana, Australia, USA, Argentina, etc. The repair cost for construction damages by ES in South Africa is estimated at R100 million annually [4]. In the United Kingdom, ES damages are evaluated at $£ 400$ million annually [5]. The American Society of Civil Engineers estimated that 25\% of houses exhibit some damages initiated by ES [6]. ES damages generate a yearly financial loss more than hurricanes, floods, tornadoes, and earthquakes put together [7]. Reference [8] revealed that soil stabilization is achieved utilizing various geotechnical techniques that modify and improve the state of the unsuitable ground where soil 
replacement is not possible for technical and environmental reasons or not cost-effective. Reference [9] reported that the expense of cut to spoil of ES during construction projects of airports, roads, buildings has kept on expanding because of the enormous cost of removal, haulage, and the increment shortage of spoil regions due to the city expansion. Besides, appropriate borrow materials keep on exhausting, with their areas getting further a lot from the location where they would be required. This situation has driven the research of reasonable methods of enhancing and utilizing ES. Soil stabilization is a geotechnical process including mechanical, chemical, or other alternative treatment methods intended to sustain stability, enhance engineering properties, limit water absorption capacity and improve compressibility of the treated soil [10]. Other studies conducted by $[11,8,12,13]$ reported that the functions of soil stabilization include: increase liquefaction resistance, fill voids, give lateral stability, reduce imposed loads, control deformations, enhance shear strength, improve bearing limit, increase density, reduce soil plasticity, reduce swelling/shrinkage potential. Figure 1 shows the different stabilization techniques of ES (mechanical stabilization, chemical stabilization). The primary objective is to review, describe, report limits and merits of mechanical and chemical treatment methods. Nonetheless, the study will further focus on cost effectiveness, geoenvironmental and standardization concerns.

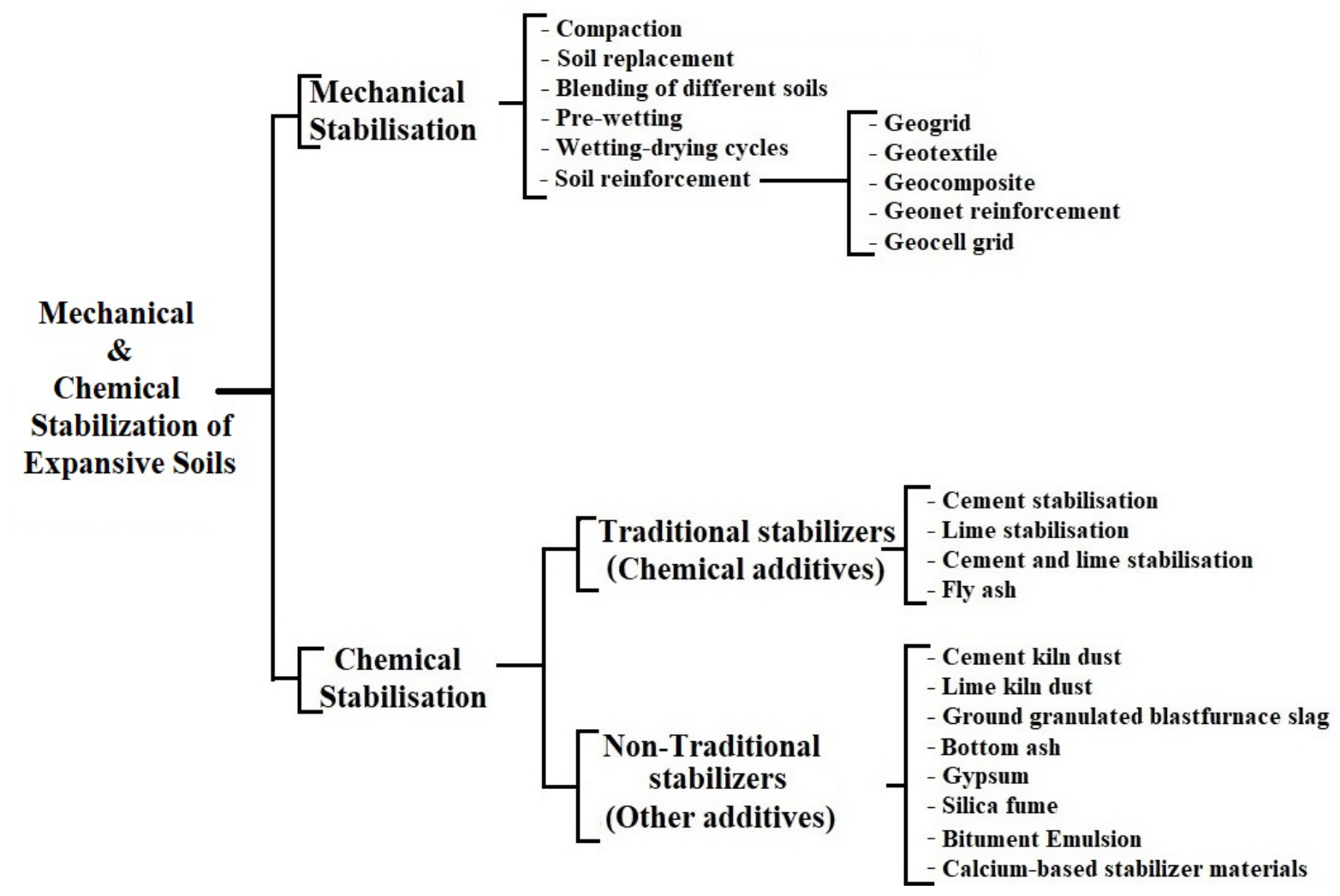

Figure 1. Mechanical and Chemical Stabilizations methods of expansive soils 


\section{Mechanical Stabilization}

The mechanical methods have been applied in engineering practice over the years for the treatment of ES. The objective of mechanical stabilization techniques of ES is the reduction of the expansion potential and swelling stress (SS) without modifying the soil chemistry [14]. Besides, the assessment of the SS of expansive soils can also be performed using the predictive model recently developed by [101].

\subsection{Compaction}

The main reason for soil compaction is to obtain a soil material that can satisfy three fundamental requirements: Abatement of the subsequent settlement of soil material under live loads. The reduction in permeability prevents an increase of water stresses inducing liquefaction issues and water content for earth dams. Finally, enhance the shear resistance and the bearing limit of the soil material. Besides, compaction influence on soil properties depends generally on the structure attained by the soil during compaction. The optimum water content $\left(\mathrm{W}_{\mathrm{OP}}\right)$ and maximum dry unit weight $\left(\gamma_{\mathrm{dmax}}\right)$ are estimated from the compaction curve. Reference [102] proposed a mathematical concept utilizing differential function $(\partial)$ and graphical technique to determine the $\mathrm{W}_{\mathrm{OP}}$ and $\gamma_{\mathrm{dmax}}$ of partially saturated fine-grained clay soils. The results revealed that the $\Delta \mathrm{W}_{\mathrm{OP}}$ and $\Delta \gamma_{\mathrm{dmax}}$ values are $<0.5 \%$ and negligible in classical soil mechanics. Nonetheless, the soil moisture deficiency values induced by $\Delta \mathrm{W}_{\mathrm{OP}}$ are important for partially saturated soils. The mathematical approach gives an accurate assessment of compaction features of partially saturated fine-grained clay soils. Reference [15] stated that the SS values on the dry side of the $\mathrm{W}_{\mathrm{OP}}$ are higher than values on the wet side, and compaction at $\mathrm{W}_{\mathrm{OP}}$ can diminish the SS by $15 \%$. Moreover, the swelling parameters, geotechnical index properties influence the SS of compacted ES. Nonetheless, there is an important effect of the kind of clay mineral on SS. Reference [16] investigated the relationship between swelling potential (SP) and plastic limit (PL). The result shows that the SP of heaving soils increases significantly when the PL increment. The investigation performed by [17] on the SP of various compacted ES placed at various initial water content (Wi) and dry unit weight confirms that the SP of compacted ES reduces when the initial water content increases (Wi). Further, the investigation conducted by [18] on semi-empirical correlations for the SS of heaving soils of Barranquilla, Colombia, reveals that the SP of compacted ES diminishes when the Wi increases. Nonetheless, at $\mathrm{W}_{\mathrm{OP}}$, the SS increases when the Wi increases. Reference [19] investigated the influence of changing $\gamma_{\mathrm{d}}$ and water content on heaving soils. The results revealed a positive exponential correlation between
SS and dry unit weight, whereas an exponential correlation was negative between the SS and the moisture content. The outcome is in line with the studies performed by $[20,21]$ reported the increment of the SS when the dry density increases. Reference [103] investigated the correlation between SS and suction of compacted expansive soils. The outcomes reveal that at $\mathrm{W}_{\mathrm{OP}}$, the $\mathrm{SS}$ values range from $177 \mathrm{kPa}$ to $326 \mathrm{kPa}$. These values are higher than the carrying capacity ( $40 \mathrm{kPa})$ usually applied to the lightweight footing. A strong correlation is observed between the SS and soil suctions with a coefficient of determination value $\mathrm{R}^{2}>80 \%$. Besides, the assessment of soil moisture deficiency can be conducted using the predictive model recently proposed by [104]. In general, compaction control can reduce the swelling capacity of heaving, and the soil suction exhibits significant influences on the soil SS.

\subsection{Soil Replacement}

Soil replacement is among the most usually applied mechanical soil stabilization procedures. The soil depth to be replaced relies on active zone depth, soil profile, regular practices, and construction standards [22]. Backfill materials should be impermeable and non-expansive. Also, backfill substances especially remolded in situ soil, should be replaced and compacted with suitable compaction parameters [23]. If the replacing soil material is permeable like gravel, coarse sand, it transmits the surface moisture to the swelling clay layer and induces differential movement equivalent to the surface. The utilization of gravel and sand as replacing soil materials is prohibited [24]. However, problematic soil replacement with a material having a better capacity to withstand loads is the best approach [25]. Finally, because of the higher replacement expenses of some undesirable soils like swelling soils, the cost-effective improvement procedure may include an efficient stabilization technique.

\subsection{Blending of Various Soils}

The mechanical stabilization includes blending of local soil with another soil of various degrees to get a targeted degree of the last mixture. It can be performed at the worksite or at different locations before the mixture is delivered to the place of work, spread, and compacted to an adequate density. Moreover, soil stabilization may include mixing soils with specified quantities of products as additives that can change the texture, gradation, shear stress, and plasticity or performing as binders for soil cementation [26,27]. The impact of the replacement of ES with mixed sandy-reused EP (extended polystyrene) is investigated by [28]. It is found that the blending of soils diminished the swelling capacity and enhanced the compaction parameters $\left(\mathrm{W}_{\mathrm{OP}}, \gamma_{\mathrm{dmax}}\right)$ upon an increment of the EP. 


\subsection{Pre-wetting}

Reference [29] reported that the pre-wetting of swelling soil has been performed in engineering practice over the years. The essential idea driving this technique is that the soil saturation induces a swell before the construction works started so that residual wetting of the soil material would be marginal to initiate defect on the foundation by keeping up a high water content condition. Reference [22] conducted a study on prewetting of ES. It was observed that the value of moisture content must be maintained high to prevent variation of the soil material volume. Reference [30] reported that, in field conditions, keeping the soil at a high constant moisture level is not easy to achieve and the technique isn't good and not generally suggested. Reference [31] reported that the technique is efficient when pre-wetted soils have hydraulic conductivity to allow the drenching procedure to perform within a limited period. Swelling soils that exhibit hydraulic conductivity cast doubt on the ability of the pre-wetting method. The common practice utilizes materials commonly known as surfactants to speed up water drainage measures through the swelling soil layer. Reference [30] stated that effective utilization of the pre-wetting technique is reported at Hawthorne clay development in Gainesville, Florida, and Yazoo clay development in Mississippi, USA. Reference [32] revealed that for pavement construction in ES, the most prewetted clay subgrade is injected with water at the depth of subgrade. After this cycle, they are either covered with a polyethylene sheet to hold moisture, kept wet by sprinkling, or built on fast. However, their utilization is getting more frequent. The combined impact of a moistened subgrade and moisture boundaries, when applied effectively, can be extremely beneficial. The utilization of moisture treatment combined with appropriate compaction is used widely.

\subsection{Wetting-Drying Cycles}

The wetting-drying cycle is not commonly described as a standardized stabilization method. However, the technique may be used to reduce the SP of ES in a specific construction project [33]. A few studies have been performed on the influence of wetting-drying cycle technique on ES. Based on the outcomes of these studies, a repeated technique may either induce an increment or reduction of expansion potential. Research works conducted by $[34,35,36]$ reported that heaving soils exposed to successive drying and wetting exhibits a considerable reduction in expansion potential. Also, other researchers like [37,38,39] have reported a contrary impact in which the cyclic procedure of wetting and drying induces a perceptible increment of SP. Wetting-drying cycles are additionally utilized to investigate the durability of chemical additives utilized in soil stabilization to comprehend the time-dependent performance of such substances under field conditions by changing drying -wetting cycle on stabilized soil material. The precedent investigations show that the plastic deformation (the difference between shrinkage and SP subject to a particular cycle) tends to decrease or reach a steady value by repeating the wetting-drying procedure.

\subsection{Soil Reinforcement}

Soil reinforcement technique is the utilization of synthesized or natural additives to enhance the properties of soils. Soil stabilization can be achieved by adding materials with higher tensile strength such as fiber to enhance the shear resistance of soil material [40,41]. Besides, soil reinforcement of poor soils includes fibrous materials such as geosynthetics (geotextile, geogrid, geonet, geocomposite, and geo-cell) or randomly distributed fibers from synthetic or natural origin [42]. Various sorts and patterns of synthetic and natural fibers utilized for soil reinforcement are outlined in Table 1.

Table 1. Summary of various natural/synthetic fibres used for soil reinforcement [43]

\begin{tabular}{cccc}
\hline Fibre source & Fibre type & $\begin{array}{c}\text { Dosage/optimal } \\
\text { content (\%) }\end{array}$ & $\begin{array}{c}\text { Fibre configuration (length) } \\
\text { / optimal length (mm) }\end{array}$ \\
\hline \multirow{5}{*}{ Natural } & Coir fibre & $0.2-1$ & $>4.75$ \\
& Coir pith & $0.5-3$ & $<4.75$ \\
& Sisal fibre & $0.25-1$ & $10-25$ \\
& Palm fibre & $0-1$ & $20-40$ \\
Jute fibre & $0.3-0.9$ & $6-18$ \\
Flax fibre & $0.6 \mathrm{a}$ & $85 \mathrm{a}$ \\
Barley-straw fibre & $0-0.35$ & $10-500$ \\
Carpet waste fibre & $1-5$ & $2-20$ \\
Pynthetic & $0.5-1.5$ & $10-30$ \\
& Polypropylene fibre & $0-10$ & $\leq 15$ \\
& Poste rubber fibre & $0-2$ & $3-12$ \\
& Glass fibre & $0.25-1$ & $10-30$ \\
& Polyethylene fibre & $0-4$ & $12-36$ \\
& Polyvinyl alcohol fibre & $1 \mathrm{a}$ & $12 \mathrm{a}$ \\
\hline
\end{tabular}


Reference [44] studied the impact of two sorts of carpet waste from various sources on swelling behaviour of compacted clays. Class 1 was exclusively designed of short fibres of nylon from sheared piles of the carpet, whereas class 2 was a combination of polyester, polypropylene, and wool got from the edge of the trimming of the carpet. The outcome revealed that for clay compacted with $10 \%$ activated bentonite sodium content at the $\gamma_{\mathrm{dmax}}$ and $\mathrm{W}_{\mathrm{OP}}$, the SS reduced from $20 \%$ at $1 \%$ class 1 fiber content. However, the SS increased for the other fiber content. Nonetheless, for class 2 fiber, the soil material SS increases remarkably, reaching a rising peak of around $83 \%$ at $3 \%$ fiber content. Further, the SS dropped with the increment in water content at steady $\gamma_{d}$ and increases with the increment of $\gamma_{\mathrm{d}}$ at constant water content.

Reference [45] examined the mechanical property of a fiber-clay composite and natural fiber. They found that incorporating fiber to strengthen the soil material induces a reduction in pre-consolidation pressure and increases swelling parameters and compressibility. In addition, the internal frictional angle and shearing stress increment upon effective and total stress.

Reference [46] investigated the enhancement in the characteristics of ES utilizing hay fibers. They discovered no significant or acceptable variation of Atterberg limits because of the incorporation of hay fibers. The $\gamma_{\mathrm{dmax}}$ diminished with the hay addition. The $\mathrm{W}_{\mathrm{OP}}$ reduces with the increment of hay content up to $1.0 \%$ then starts to decrease. The shrinkage limit decreases upon an increment of the hay content up to $1.0 \%$ after reduces. The unconfined compression stress diminished with the increment of hay content to soil proportion. The direct shear stress increased remarkably upon the addition of hay. The tensile stress of air-dried blend increased with hay addition and the expansion diminished upon the addition of hay.

Reference [47] studied the impact of waste rubber fibers on geotechnical properties of clay. The fibers of rubber were added within the range of $0 \%-10 \%$ contents with $2.5 \%$ constant addition by weight of the dry soil material. The outcome of density-moisture correlation exhibited a progressive decrease in both $\mathrm{W}_{\mathrm{OP}}$ and $\gamma_{\mathrm{dmax}}$ from $20.1 \%$ to $18.25 \%$ and from $16.35 \mathrm{kN} / \mathrm{m}^{3}$ to 14.78 $\mathrm{kN} / \mathrm{m}^{3}$, respectively. The uniaxial compressive stress (UCS) exhibited a slight increment from $60.59 \mathrm{kPa}$ to $62.69 \mathrm{kPa}$ at $2.5 \%$ fiber of rubber content. Nonetheless, further augmentation of rubber fiber diminished the axial stress peak with a maximum decrease of about $21.7 \%$ at $10 \%$ fiber of rubber content. The soaked CBR continuously dropped with fiber rubber content, whereas the unsoaked CBR reaches a peak of around $38.6 \%$ at $2.5 \%$ fiber rubber addition. The SS of ES gradually diminished with increment in fiber content from $70.12 \%$ for the natural soil material to $39.58 \%$ at $10 \%$ fiber of rubber content.
The stabilization of ES can be performed by adding higher tensile natural or synthetic fibers as reinforcement. The literature review revealed that this technique reduces the swelling/shrinkage potential and soil settlement. Moreover, enhance the mechanical property such as the shear strength and bearing limits.

\subsection{Merits and Limitations of Mechanical Stabilization}

References [12,48,13,43] investigated the stabilization of ES and reported the merits of mechanical stabilization as follows: During rainy seasons, climate-related deferrals can be decreased by stabilizing the soil and proceed with site work, soil stabilization can positively impact the construction schedule and save the cost of waiting for good weather to continue with work, It can serve as a viable waste management option in contrast to landfills by the utilization of waste materials; It doesn't represent the danger of giving an adverse environmental impact from the discharge of potential unhealthy compounds, the application can be quick when the engineering characteristics of soils are not considered critical; It doesn't need time-consuming standardized lab experiments when supplements substances are unincluded; The procedure of application is relatively simple and doesn't require highly trained staff for implementation. References [12,13,43] reported the limitations of mechanical stabilization are as follows: Mechanical techniques are not usually independent techniques and regularly need to be enhanced with chemical stabilization. It includes delayed physical activity to implement in-situ when quality control is fundamental, which could be time-consuming. It may not be viewed as adequate when the soil material condition is critical such as heaving soils. The predicted result might be unreliable for wetting-drying/pre-wetting cycles.

\section{Chemical Stabilization}

Chemical stabilization is the commonly utilized technique for ES treatment. The purpose of the chemical stabilization of soils is to enhance their stability by increasing grain size particles of soil material, decreasing plasticity index, swelling-shrinking potential, and cementation. Soil stabilization is performed by adding a specific chemical compound amount to the ES.

\subsection{Traditional Stabilizers (Chemical Additives)}

\subsubsection{Cement stabilization}

Portland cement is a hydraulic binder, which means it hardens and reacts chemically upon water addition. Reference [49] reported that the common techniques utilized in chemical stabilization consisted of blending the soil material with cement to obtain soil cement. Soil 
cement is a combination of soil, estimated quantities of Portland concrete, and water compacted to the targeted density. Portland cement is utilized to enhance and modify the quality of soil material, transform the soil material into a cemented mass with an increment of durability and shear resistance. Reference [50] reported that concrete treatment slightly increases the $\gamma_{\mathrm{dmax}}$ of sand and highly plastic clay and diminishes the $\gamma_{\mathrm{dmax}}$ of silt [51]. Another investigation conducted by [52] reveals that cement increases the $\mathrm{W}_{\mathrm{OP}}$ and reduces the $\gamma_{\mathrm{dmax}}$ of sandy soils [52]. Cement addition reduces the LL, increases the PL, and ultimately reduces the PI [51]. The other relevant impacts of stabilization using soil-cement are the decrease in SP and shrinkage, the increment in elastic modulus, shear stress, and the resistance to the effect of dampness, thaw, and freeze. Reference [53] reported that SS reduces when stabilizer content increases in specimens treated with cement. During cement stabilization, the compaction of soil-cement specimens is conducted in two hours of primary mixing. The strength obtained during soil compaction might be smaller than the ultimate stress of the soil-cement samples [54]. Nonetheless, the stabilized ES material will still be gaining strength throughout a few days $[55,56]$.

\subsubsection{Lime stabilization}

It is a well-established practice to utilize lime to enhance the engineering behaviour of expansive clayey soils. Generally, fine-grained treated with exhibit decrease plasticity, enhancement of workability, and decrease volume variations characteristics. The three kinds of limes utilized to enhance the soil parameters include hydrated lime (calcium hydroxide- $\mathrm{Ca}(\mathrm{OH})_{2}$, hydrated lime slurry, and quicklime (calcium oxide-CaO). The impact of lime in ES includes: reduction of consistency limit, expansivity potential, and $\gamma_{\mathrm{dmax}}$ of soil material, but increase the shrinkage limit, strength, and $\mathrm{W}_{\mathrm{OP}}[49,57]$. It improves the workability and compact ability of subgrade soils [58]. Lime diminishes the plasticity index, $\gamma_{\mathrm{dmax}}$, and SP of soil material. Besides, lime increases the shear strength, $\mathrm{W}_{\mathrm{OP}}$, and shrinkage limit [49,57]. Lime stabilization technique improves the hydro-mechanical parameters of soil material like shear strength, higher resistance to crack, permanent deformation, and fatigue. Lime improves resilient properties, decreases SS, and protects the soil from destructive impacts of water. The most significant enhancement in these properties is shown in medium to high plastic clay $[59,60]$. The efficiency of lime treatment in soil material is mainly related to lime content, soil type, curing time, clay minerals, and soil $\mathrm{pH}$ [61]. Nonetheless, not all soil materials display enhanced strength parameters. It should be mentioned that the qualities of soil lime combination are subject to numerous factors include lime type, Soil type, lime content, and conditions of curing that are the most significant [26]. Lime will essentially react with medium and fine-grained soils to improve workability, decreased swell, and incremented shear stress. The improvement of soil characteristics results from three fundamental chemical processes [62]: 1.flocculation-agglomeration and Cation trade 2 . Carbonation, and 3. Cementation (pozzolanic response). Reference [63] Stated that soil stabilization by lime increases the resilient modulus value of soil material by about $10 \%$ or more, enhances the shear strength value by about $20 \%$. The strength continues to increase over time even after the duration of load or environmental destruction (self-restoration) and long-term service life of upon harsh environment over decades. Figure 2 describes the soil modification upon the addition of lime.

Reference [64] assessed the cyclic feature of ES stabilized with lime utilizing the modified odeometer. The results show that the issue of the cyclic features of ES is neglected in the stabilization process. However, the cyclic features of ES material are likewise significant when the soil stabilization is performed, as the durability of chemical compounds is critical for long-term stabilization impact. Moreover, further studies on lime behaviour at the microstructural level can contribute to a good understanding of the potential stabilizer and hydro-mechanical properties of the stabilize soil clay matrix.

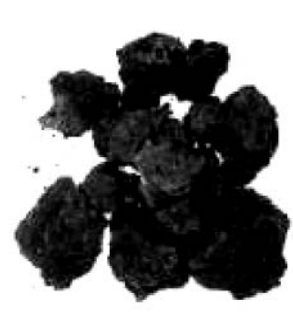

Before

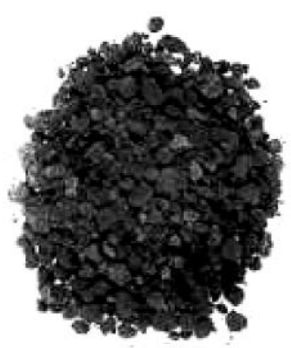

After
Figure 2. The visual influence of lime addition [63]

\subsubsection{Cement and lime stabilization}

Cement and lime are utilized to enhance the hydro-mechanical characteristics and handling process of soils during construction works [65]. Mixing soft soils or ES with cementitious material such as lime and cement is an efficient method to mitigate the swell shrink. References [66,67] utilized various rates and mixed pozzolana cement and lime to stabilize ES. The SP includes the percentage of swelling (swelling load technique and constant volume technique). The outcomes exhibited changes in various soil behaviour upon the variation of chemical substances and the decrease of SP within the stabilized soil material. Finally, lime decreases the SP, whereas cement increases the SP. Reference [68] assessed the swelling organic soils, the optimum quantity of cement for soil-lime, and soil-cement were determined within the range of $3 \%$ to $6.5 \%$ (related to soil nature) with $1035 \mathrm{kPa}$ UCS after a week of curing. They noticed that the organic matter of soils increases the $\mathrm{W}_{\mathrm{OP}}$. They 
recorded a decrease of $\gamma_{\mathrm{dmax}}$ of treated swelling organic soils because of the $\gamma_{\mathrm{dmax}}$ reduction in soil. Lime induces a significant reduction in plasticity compared to cement, and the augmentation in the UCS for soil material treated with the chemical additive was marginal for lime and even diminished for cement after a curing period of 28 days. Reference [69] has mentioned observable facts to the organic matter of the ES material. They stated that lime treatment of swelling soil containing 7\% lesser organic matter induced significant enhancement in the UCS to $893 \mathrm{kPa}$ contrasted with other different nature of ES specimen. Reference [53] examined the stabilization of over-consolidated swelling material with different lime-cement blending proportions. The addition of stabilizers reduced the SP of soil from a greater methylene blue value above two. The CBR values increment with soil treatment. $8 \%$ lime and $2 \%$ cement induce the optimal results for soaked CBR. $4 \%$ lime and $8 \%$ cement produce the optimal results for un-soaked CBR. The direct shear test revealed that $8 \%$ cement and $4 \%$ lime induce the optimal value to enhance the bearing limit.

\subsubsection{Fly ash}

Fly ash (FA) is extracted by electrostatic precipitators of filter bag from the flues gases of furnaces fired with pulverized coal. Fly ash is divided into two classes related to the presence of calcium content. Class C fly ash (CFA) usually has a calcium percentage above $20 \%$, and it is originated from sub-bituminous coal. Class F fly ash (FFA) resulted from the burning of bituminous coal, usually with a calcium percentage above $10 \%$. References [66,70] investigated the impacts of adding lime and FFA upon the ES behaviour and noticed positive outcomes. Cement and FFA stabilization of swell soil is examined by [71]. The impact of 3\% FA and 9\% cement is better than 12\% cement related to soil stabilization. References $[72,73,74]$ investigated the effect of CFA addition in swell soils with various geotechnical parameters and had obtained varied success. Reference [75] examined the swell soil stabilization utilizing a different fraction of FA. The outcome shows that the FA augmentation in the soil-FA mixture induces a significant reduction of free swell ratio (FSR) value and PI values. The SP is directly proportional to the Atterberg limits. Thus, influence the expansive behaviour of the soil-fly ash mixture. Finally, FA decreases the SS and enhances the shear resistance of ES. Reference [76] investigated the stabilization of ES utilizing different FA fractions. The CBR test is performed by the $\mathrm{W}_{\mathrm{OP}}$ obtained from the compaction test. After that, the CBR tests are conducted using differents FA contents and water content required for the optimum FA and the water content necessary for the maximal value of CBR. From the test outcomes, $16 \%$ of FA and $17.8 \%$ of water substance give the maximal value of CBR. The CBR value of the natural soil is about 2.05 (poor condition), and the CBR of the stabilized soil using FA is
31.5 (good condition). Therefore the stabilized soil can be utilized as base or sub-base in pavement design.

\subsection{Non-Traditional stabilizers (Other Additives)}

\subsubsection{Cement kiln dust}

Cement kiln dust (CKD) is produced in a huge amount by the cement industry. Over the years, investigations are performed on the utilization of CKD in soil stabilization, the addition of CKD to initial $\mathrm{pH}$ value, etc. Reference [77] investigated the influence of CKD on hydro-mechanical properties of ES. Soil specimens are tested with CKD from $0 \%$ to $25 \%$ of dry-weight soil. The outcome exhibited an important increment in soaked UCS and CBR values. The SP diminishes from $31 \%$ to $5 \%$. Compaction test revealed an increment $\gamma_{\mathrm{dmax}}$ from 1.73gm.cc ${ }^{-1}$ to $2.03 \mathrm{gm} \mathrm{cc}^{-1}$ and a considerable reduction in $\mathrm{W}_{\mathrm{OP}}$ from $20.04 \%$ to $10.94 \%$. Permeability is found to increases from $4.80 \times 10^{-4} \mathrm{~cm} . \mathrm{s}^{-1}$ to $1.43 \times 10^{-3} \mathrm{~cm} . \mathrm{s}^{-1}$. Conclusively, the CKD improved the desirable hydro-mechanical properties of ES. Vivek Singh et al. [78] investigated the influence of CKD addition on compaction characteristics of ES. The results show that the $\mathrm{W}_{\mathrm{OP}}$ of $\mathrm{ES}$ diminishes and $\gamma_{\mathrm{dmax}}$ increments upon addition of CKD. There is an important reduction of the swelling parameters of the soils. The FSR values diminish from $31 \%$ to $5 \%$, demonstrating that the SP has decreased from high to low. The soaked CBR values increment upon addition of CKD content. The incorporation of 25\% CKD into ES increases the CBR from $1.514 \%$ to $3.54 \%$. The soil permeability increases from $4.80 \times 10^{-4} \mathrm{~cm} . \mathrm{s}^{-1}$ to $1.43 \times 10^{-3} \mathrm{~cm} \cdot \mathrm{s}^{-1}$. The addition of CKD enhances the UCS. The UCS of stabilized soil specimens significantly incremented from $142 \mathrm{kN} / \mathrm{m}^{2}$ to $178 \mathrm{kN} / \mathrm{m}^{2}$. Reference [79] studied the stabilization of ES using CKD. Lab tests are conducted using non-traditional stabilizer CKD to improve the hydro-mechanical behaviour of ES with partial substitution by CKD $(5 \%, 10 \%, 15 \%, 20 \%$, and $25 \%)$ upon various curing periods $(1,3,7,14$ and 28 days). The outcomes revealed an enhancement of soil properties upon CKD addition with curing.

\subsubsection{Lime kiln dust}

Reference [80] carried out a large-scale field study to assess the efficiency of the post-construction work of road stabilized with lime kiln dust (LKD) with at least five years service life. To determine the stiffness, the strength of the stabilized ES, six areas are selected for dynamic cone penetration test, standard penetration test, and falling weight deflectometer test. Moreover, soil sampling is performed utilizing split spoon samplers and run in the lab for geotechnical index parameters and compared to natural soil material. They found that the addition of LKD diminished the plasticity of soil material significantly. Long-period enhancement of soil is validated because the lime from LKD is available in the soil material after 11 
years of pavement service life. Conclusively, the LKD is a reliable and efficient non-traditional stabilizer for pavement sub-based material and offered excellent quality control for the construction and repair works. Reference [81] Investigated the use of LKD to stabilize the clay pavement material. UCS, Proctor compaction test, non-damaging test modulus, and thermal conductivity test are conducted on modified soil material. They found that the LKD is an efficient stabilizer for clay soil material and could raise the UCS and stiffness under smaller mixing ratios of $\mathrm{W}_{\mathrm{OP}}(4 \%$ and $8 \%)$. However, the $\gamma_{\mathrm{dmax}}$ diminished upon the increment of the LKD mixing ratio.

\subsubsection{Ground granulated blast furnace slag}

Reference [82] attempted to enhance the soil material properties of ES utilizing GGBS as an alternative to lime or concrete. Lab tests are performed on local Indian ES with GGBS mixed with ES in various ratios. Soil samples are compacted at the $\mathrm{W}_{\mathrm{OP}}$ and $\gamma_{\mathrm{dmax}}$ and cured during 7,14 , and 28 days and their UCS measured. The enhancement of the strength relies upon the quantity of GGBS utilized, and the impact of curing time is marginal. Moreover, the initial tangent modulus increments with an increment of GGBS. Reference [83] conducted the stabilization of clayey soils utilizing five kinds of GGBS at a $5 \%$ ratio as suggested by Reference [84]. They noticed positive outcomes such as the decrease of SP, strength volumetric capacity, and higher CBR compared to natural soils. Reference [85] studied the stabilization of soil using GGBS. The addition of the GGBS in stabilized soil specimens induced the increment of UCS values. The augmentation is about $28 \%$ from the UCS value of natural soil upon the addition of $9 \%$ on the mix.

\subsubsection{Bottom ash}

Reference [86] investigated the influence of bottom ash on ES for pavement construction. The assessment of geotechnical properties is conducted through the Proctor compaction test, consistency limit test, CBR test, and UCS test. Soil specimens are prepared at different fractions of bottom ash as follows: $30 \%, 25 \%, 20 \%, 15 \%$, $10 \%$, 5\%. The outcomes revealed that the compaction characteristics $\left(\mathrm{W}_{\mathrm{OP}}, \gamma_{\mathrm{dmax}}\right)$ of stabilized ES are greater than natural soil by adding $30 \%$ bottom ash. The consistency limits of stabilized ES are smaller than the standard value by adding 30\% bottom ash. The UCS values of stabilized ES are greater than natural soil by adding 30\% bottom ash. By adding $20 \%$ of bottom ash, the CBR value is higher than the CBR of natural soils. The addition of $30 \%$ of bottom ash enhances the hydro-mechanical characteristics of soil materials.

\subsubsection{Gypsum}

Reference [87] investigated the stabilization of ES using gypsum. Samples are prepared at the $\mathrm{W}_{\mathrm{OP}}$ with various gypsum content ratios (2.5, 5, 7.5, and 10) and bentonite. Lab tests which include Atterberg limits, CEC (Cation exchange capacity), FSR test, and UCS test are conducted to determine the hydro-mechanical properties on stabilized and non-stabilized tested through standard proctor test at $\mathrm{W}_{\mathrm{OP}}$ and cured for a week. They found that the stabilization of ES with gypsum is more cost-effective than lime and noticed an augmentation of UCS of bentonite with a gypsum ratio equal to or less than $5 \%$ optimal outcomes. However, the utilization of gypsum in soil stabilization can induce groundwater pollution.

\subsubsection{Silica fume}

Reference [88] Stabilized ES soils utilizing silica fume to enhance its resistance against cyclic drying and wetting conditions and durability. The swelling characteristics of the mixture of expansive clayey soil and silica fume are conducted in a laboratory. The SP and the SS test are performed in a one-dimensional consolidometer oedometer. Alongside the swell tests, the stabilized ES are subjected to the specific surface area, cation exchange capacity (CEC), compaction characteristics, and consistency test. The outcomes show that the utilization of silica fume in stabilization soils decreases the CEC, specific surface area, $\gamma_{\mathrm{dmax}}$ and incremented the $\mathrm{W}_{\mathrm{OP}}$ and $\mathrm{pH}$. The SS and SP diminished significantly with increment in silica fume. Besides, the application of silica fume in ES stabilization enhances its durability by reducing the SP even upon the drying and wetting cycle. Reference [89] reported the beneficial outcomes of enhancing the properties of ES by silica fume stabilization.

\subsubsection{Bitument emulsion}

Reference [90] conducted a review on ES treated utilizing bitumen emulsion. Laboratory tests are related to the fundamental characteristics of soil material and its strength in terms of CBR. The outcomes reveal the compaction characteristics $\left(\mathrm{W}_{\mathrm{OP}}, \gamma_{\mathrm{dmax}}\right)$ of ES increments upon addition of $6 \%, 7 \%$, and $8 \%$ bitumen emulsion to the soils. The permeability of stabilized soil utilizing the bitumen emulsion is higher than natural soils. The addition of the bitumen emulsion on soil material improves the CBR values. The utilization of bitumen emulsion on pavement construction reduces the thickness of the sub-grade, cost of soil material, amount of soil material, etc. Bitumen is less in cost and easily accessible. The highest limit of replacement of bitumen emulsion in soil material is $8 \%$ only since at $9 \% \mathrm{CBR}$, and $\gamma_{\mathrm{dmax}}$ values reduce. Finally, when the bitumen emulsion is smaller than $8 \%$, the treated soil material exhibits good soil waterproofing and strength enhancement.

\subsubsection{Calcium-based stabilizer materials}

Reference [91] reviewed the past four decades the techniques to stabilize highly ES utilizing calcium-based stabilizer materials (CSMs). The impact of the adequately 
demonstrated CSMs on the geotechnical, engineering, and microstructural properties of stabilized ES are analyzed. Moreover, a new investigation related to the utilization of environmentally friendly and non-conventional stabilization materials and methods is discussed. The results of the literature review are as follows:

- The ES microstructure is a fundamental parameter in assessing the compressive strength characteristics, shrink-swell parameters, and the environmental potential in various soil stabilization construction projects. A suitable and best selection of stabilizers should be related to their resulting impact on their microstructure.

- The microstructure impacts the rate of hydration, the pozzolanic responses in the polymerization procedure. Cementation plays a significant part in the necessary period and state of soil curing. The optimal dosage, the application should be defined before CSM stabilization.

- Although cement being the broadly utilized CSM, mindful of the costs and challenges of $\mathrm{CO}_{2}$ discharge and related harmfulness levels in treated soils, lime with other pozzolans is an effective selection to stabilize ES.

\subsection{Merits and Limitations of Chemical Stabilization}

A few researchers investigated the merits of chemical stabilization. Reference [48] reported a significant saving when stabilizing an existing sub-grade rather than changing the current sub-grade with appropriate soil material. Moreover, the stabilization of sub-grade decreases the section of asphalt paving base material and reduces the cost. Reference [43] stated that chemical stabilization is an efficient method regardless of the properties of soil materials. The procedure is time-dependent on the chemical additive response, which happens immediately after primary mixing, and it is not time-consuming. The expected results are obtained through standard laboratory tests. The mass of chemical additives required for an efficient stabilization process is generally small, making it cost-effective. This method serves as a management waste technique to reuse industrial by-product materials.

Researchers investigated the limitations of chemical stabilization. Reference [92] stated that chemical stabilization lowers the compaction of clays, a significant loss in the $\gamma_{\mathrm{dmax}}$ and increment of $\mathrm{W}_{\mathrm{OP}}$. Moreover, manufacturers and merchants of these compounds make claims of how they work around and inside the clay. However, few compounds are tested and assessed independently. Before the utilization of stabilizer, it should be tested by an independent lab; using similar testing sequences for all compared agents, financial analysis of his utilization should be considered. Reference [93] reported that the manufacture of chemical substances can induce hazards to the environment and can be very expensive at times. Besides, a specific additive mix efficiency can be determined if tested in the laboratory for ES material. Reference [43] reported that the utilization of the toxic product produces some harmful substance, and further the hazard of groundwater pollution through the leachate of dangerous substances. These products may not be appropriate when the expense of chemical substance gets restrictive according to the amount required to stabilize soil efficiently. The application in situ might be practically inefficient if field conditions change significantly from that model during the lab simulation tests. Based on the quality of the additive utilized and its application, some properties which could have unfavorable environmental impacts should be verified. The properties include the soil material $\mathrm{pH}$ value, diffusion of toxic products such as carbon, etc., and leachate to groundwater of heavy metals. When the condition is not favorable, the impact of chemical stabilization may get detrimental. For example, soil stabilization using lime-sulfate induces cracks, etc.

\section{Expansive Soil Stabilization Problems}

\subsection{Geoenvironmental Problems}

During the stabilizing ES using mechanical methods and chemical methods, the geoenvironmental issues are essentially related to the chemical methods. The utilization of traditional stabilizers and non-traditional stabilizers leads to environmental pollutions (Groundwater pollution, Land/Soil pollution). Nonetheless, mechanical stabilization exhibits a marginal influence on environmental pollution. Nevertheless, mechanical stabilizations are not usually independent techniques and regularly improved with chemical stabilization in practice. The treatment of ES using chemical stabilizers can be harmful to the natural environment if not conducted properly. There is a need for engineers to perform the geoenvironmental investigation as appropriate to their studies on the stabilizer used for the assessment to be sustainable. Reference [94] utilized 17\% rice husk ash (RHA) and $2 \%$ bentonite mixed with clay as a liner landfill to diminish chromium leachate. Reference [95] used the sawdust-stabilized clay as a landfill liner to contain lead and cadmium leachate. Reference [96] conducted a study to check if the level of iron from the stabilizer that can contaminate the groundwater is within the drinking water standard proposed by WHO. Another technique applied to prevent the seepage of heavy metals into groundwater is the utilization of designed landfills like landfill liners. These liners play the role of barriers to absorb heavy metals and accordingly keep them from groundwater contamination. Reference [43] reported that 
the soil treatment that required a hydrogen sulfide or high-carbon manufacturing additive is prohibited. The utilization of materials made out of heavy metals that can pollute the groundwater by filtering is not accepted.

\subsection{Standardization Problems}

The lack of standards in the treatment of ES is a significant problem in geotechnical engineering. A comprehensive guideline on ES treatment utilizing different materials and methods has not yet been developed. Therefore, specialists in the domain of soil treatment must work together toward a solution to this matter. Nonetheless, a few endeavors have been performed to develop in this regard. Reference [97] proposed a manual that presents the procedures to apply the coal fly ash as a chemical additive. Reference [98] also published guidelines for soil treatment utilizing fly ash material. References [99,100] proposed guidelines limited to the traditional stabilizers and specific applications. Based on the available research outcomes, practical experience, and the potential application of numerical models, it is possible to propose comprehensive and suitable standards related to the stabilization of ES in engineering practice. Numerical models can be used to predict an optimized stabilization technique utilizing various combinations of stabilizers. These models are less time-consuming, cost-effective compared to traditional laboratory tests.

\section{Concluding Remarks}

A comprehensive review in ES treatment using mechanical and chemical methods is conducted in this research work, and the concluding remarks are as follows:

- The treatment of ES utilizing mechanical stabilization, Chemical stabilization (Chemical additives, other additives) enhances the characteristics of ES.

- Stabilization can be performed more economically and more completely initially than when repairs are needed to keep up with an unstable situation.

- The behaviour of stabilized soils subjected to repetitive loadings is restricted in the literature.

- Utilization of artificial intelligence such as neuro-fuzzy, artificial neural networks, genetic programming to predict an optimized stabilization technique utilizing combinations of stabilizers is limited in the literature.

- There are potential geoenvironmental problems related to soil chemical treatment. Hence, the assessment to guarantee that the stabilization technique is sustainable and environmentally friendly is required.

- The contaminant influences on the mechanical characteristics of treated soils, durability, mineralogy characteristics, and stabilization cost are limited in the literature.

- The efficiency and the proportion of any specific additive mix to optimize the outcomes depend significantly on the type of ES, soil chemistry, mineralogy of clay, physical composition, initial moisture content, moisture variation, plasticity, etc.

- ES is a typical case of unsaturated soils. Researchers have discussed the impacts of stabilization on index properties, compaction properties, UCS, CBR, and swelling properties of ES. Very few studies are conducted on the splitting tensile strength, shear strength, stiffness, hydraulic conductivity properties, and the impact of matric suction on mechanical characteristics of treated soils.

- Forthcoming studies on the treatment of ES using chemical and mechanical techniques should be performed considering the remarks above-mentioned.

\section{REFERENCES}

[1] Abu Siddique, M.Alomgir Hossain, "Effects of lime stabilisation on engineering properties of an expansive soil for use in road construction," Journal of Soc for Trans and Traffic Studies, vol. 2, no. 4, pp. 1-9, 2013. http://thaitransport.org/JSTS/

Vol_2_issue_4/JSTS_Vol_2_Issue_4.pdf\#page=5 (accessed March.18,2021).

[2] AB Salahudeen, Adrian Oshioname Eberemu, Kolawole Junwonlo Osinubi, "Assessment of cement kiln dust- treated expansive soil for the construction of flexible pavements," Geotechnical and Geological Engineering, vol. 32, no.4, pp. 923-931. 2014. DOI: 10.1007/s10706-014-9769-0.

[3] Ali Akbar Firoozi, C.Guney Olgun, Ali Asghar Firoozi, Mojtaba Shojaei Baghini, "Fundamentals of soil stabilization," International Journal of Geo-Engineering, vol. 8, no. 1, pp. 26. 2017, DOI: 10.1186/s40703-017-0064-9.

[4] Tony Williams, John Terry Pidgeon, Peter William Day, "Expansive soils: problem soils in South Africa-state of the art," Civil Engineer in South Africa, vol. 27, no. 7, pp. 367-401, 1985.

[5] Richard Driscoll, Mike Crilly, "Subsidence Damage to Domestic Duilding: a good technical guide," BRE Press, 2000. London,UK.

[6] D Jones Lee, Jefferson Ian, "ICE Manual of Geotechnical Engineering, "Institution of civil Engineers, vol. 33, pp. 413-438. 2012.

[7] John Nelson, Deborah Miller, "Expansive soils: problems and practice in foundation and pavement engineering, " John Wiley and Sons. 1997.

[8] V Elias, J Welsh, J Warren, R Lukas, JG Collin, RR Berg, "Ground Improvement Methods," FHWA NHI-06-020, vol. 2, no. pp. 1056, 2006.

[9] Charles K Kabubo, Sixtus K Mwea, Sylvester O Abuodha, 
Zachary A Gariy, "The effect of heat on the properties of expansive clay soil, " International Journal of Science and Research, vol. 6, no.1, pp. 464-469, 2015, DOI: $10.21275 / 28121602$.

[10] Cyrill M Harris, "Dictionary of Architecture and Construction,". Edited by Cyril M. Harris, 2005. USA.

[11] GA Munfakh, "Ground improvement engineering-the state of the US practice: part 1. Methods,". Proceedings of the ICE-Ground Improvement, vol .1, no .4, pp. 193-214, 1997. DOI:10.1680/gi.1997.010402.

[12] Seyed Abolhassan Naeini, Bahman Naderinia, Ehsan Izadi, "Unconfined compressive strength of clayey soils stabilized with waterborne polymer," KSCE Journal of Civil Eng, vol. 16, no. 6, pp. 943-949, 2012. DOI 10.1007/s12205-012-138 8-9.

[13] Braja M Das, "Principles of foundation engineering,"Cengage learning, 2015.

[14] J Antonio H Carraro, Jesse Dunham-Friel, Micah Smidt, "Beneficial use of scrap tire rubber in low-volume road and bridge construction with expansive soils, No.USDOT-MPC/274, Colorado State University, Dept of Civil and Env Eng, 2010.

[15] Armand Augustin Fondjo, Characterization of SS and soil moisture deficiency relationship for expansive unsaturated soils, Master dissertation, Central University of Technology, Free State. 2018.

[16] Jahanzaib Israr, Khalid Farooq, Hassan Mujtaba, "Modelling of swelling parameters and associated characteristics based on index properties of expansive soils," Pakistan Journal of Eng and Appl Sciences, vol. 15, pp. 1-9, 2014.

[17] Kinjal Rank, Jaydeep Bhanderi, Keyur Nagecha,"SP of different expansive soil placed at different dry density and initial water content," International Journal of Advance Engineering and Research Development, vol. 2, no. 3, pp. 1-7, 2015.

[18] Victor Cantillo, Mercado Vicente, Pájaro César,"Empirical correlations for the SS of expansive clays in the city of Barranquilla Colombia" Earth Sciences Research Journal, vol. 21, no. 1, pp. 45-49, 2017. DOI: 10.15446/esrj.v21n1.60226.

[19] Kehzen Yan, Luocheng Wu, "Swelling behaviour of compacted expansive soils, "In proceeding: GeoHunan international conference, ASCE, vol. 192, pp. 1-6, 2009. DOI: $10.1061 / 41044(351) 1$.

[20] Fernando AM Marinho, Mônica M Stuermer, "The influence of the compaction energy on the SWCC of a residual soil," In proceeding: Advances in unsaturated geotechnics, proceedings of sessions of geo-denver, ASCE, pp. 125-141, 2000. DOI: $10.1061 / 40510(287) 8$.

[21] Valéry Ferber, Jean-Claude Auriol, Yu-Jun Cui, Jean-Pierre Magnan, "On the SP of compacted high plasticity clays," Engineering Geology, vol. 104, no. 3-4, pp. 200-210, 2009.

[22] Fu Hua Chen," Foundations on expansive soils," Elsevier Science, vol. 12, 2012.

[23] A Ardani, "Expansive Soil Treatment Methods in Colorado, Final Report," Colorado Department of Transportation.199 2
[24] Magdi Zumrawi, "Construction problems of light structures founded on expansive soils in Sudan," International Journal of Sc and Res, vol. 4, no. 8, pp. 896-902, 2015.

[25] Tuncer B Edil, Craig H Benson, M Bin-Shafique, Burak F Tanyu, Woom-Hyung Kim, Aykut Senol, "Field evaluation of construction alternatives for roadways over soft subgrade," Transportation Research Record, vol. 1786, no.1, pp. 36-48, 2002.

[26] Joint Departments of the Army and Air Force,"Soil Stabilization for Pavements," TM 5- 822-14/AFMAN 32-8010, 1994. USA.

[27] Mohamad Nidzam Rahmat, Norsalisma Ismail, Mohammad Redzwan Raffe, "Strength properties of sustainable palm oil fuel ash stabilized landfill," In Proceedings of the Colloquium on Administrative Sc and Tech, Singapore, Springer, pp. 533-544. 2015. DOI: 10.1007/978-981-458545-3_51.

[28] Gihan E Abdelrahman, "New replacement formations on expansive soils using recycled EPS beads," Proc. 18th ICSMGE. 2013.

[29] Tom Schanz, Mohamd BD Elsawy, "Swelling characteristics and shear strength of highly expansive clay-lime mixtures: A comparative study," Arabian Journal of Geosciences, vol. 8 , no. 10, pp. 7919-7927. 2015. DOI: 10.1007/s12517-014-1703-5.

[30] John D Nelson, Kuo Chieh Chao, Daniel D Overton, Erick J Nelson," Foundation engineering for expansive soils," Wiley, vol. 416, 2015. New York.

[31] Braja M Das,"Geotechnical engineering handbook," J. Ross publishing, 2010. USA.

[32] Thomas M Petry, Dallas N Little, "Review of stabilization of clays and expansive soils in pavements and lightly loaded structures-history, practice, and future," Journal of mat in civil eng, vol. 14, no. 6, pp. 447-460, 2002. DOI: 10.1061/(ASCE)0899-1561(2002)14:6(447).

[33] Hojjat Ahmadi, Hassan Rahimi, Maryam Ebrahimi Rostami, "Control of swelling of soil under canal lining by wetting and drying cycles,". Irrigation and Drainage, vol. 61, no.4, pp. 527-532, 2012. DOI: 10.1002/ird.1666.

[34] Amin Soltani, Abbas Taheri, Mehdi Khatibi, AR Estabragh, "Swelling potential of a stabilized expansive soil: A comparative experimental study," Geotechnical and Geological Engineering, vol. 35, no. 4, pp. 1717-1744, 2017. DOI: $10.1007 / \mathrm{s} 10706-017-0204-1$.

[35] AR Estabragh, Bijan Parsaei, AA Javadi, " Laboratory investigation of the effect of cyclic wetting and drying on the behaviour of an expansive soil," Soils and Foundations, vol. 55, no. 2, pp. 304-314, 2015. DOI: 10.1016/j.sandf.2015.02 .007 .

[36] T Thyagaraj, Samuel Zodinsanga, "Swell-shrink behaviour of lime precipitation treated soil," Proceedings of the ICE-Ground Improvement, vol. 167, no. 4, pp. 260-273, 2014. DOI: 10.1680 /grim.12.00028.

[37] Salma Tawfiq, Zalihe Nalbantoglu, "Swell-shrink behaviour of expansive clays," Near East University, Nicosia, Cyprus, pp. 336-341, 2009.

[38] AR Estabragh, H Rafatjo, AA Javadi, "Treatment of an 
expansive soil by mechanical and chemical techniques," Geosynthetics International, vol. 21, no. 3, pp. 233-243. 2014. DOI: $10.1680 /$ gein.14.00011.

[39] AR Estabragh, Amin Soltani, AA Javadi, "Effect of pore water chemistry on the behaviour of a kaolin-bentonite mixture during drying and wetting cycles, "European Journal of Environmental and Civil Engineering, 2018; vol. 24, no. 7, pp. 895-914. 2018. DOI: 10.1080/19648189.2018 .1428691 .

[40] Amin Chegenizadeh, Hamid Nikraz, "Investigation on strength of fiber reinforced clay,"Advanced Materials Research, vol. 261, pp. 957-963, 2011.

[41] BVS Viswanadham, BR Phanikumar, Rahul V Mukherjee, "Swelling behaviour of a geofiber-reinforced expansive soil," Geotextiles and Geomembranes, vol. 27, no. 1, pp. 73-76, 2009. DOI:10.1016/j.geotexmem.2008.06.002.

[42] Sayyed Mahdi Hejazi, Mohammad Sheikhzadeh, Sayyed Mahdi Abtahi, Ali Zadhoush, "A simple review of soil reinforcement by using natural and synthetic fibers," Construction and B.M, vol. 30, pp. 100-116. 2012. DOI: 10.1016/j.conbuildmat.2011.11.045.

[43] Chijioke Christopher Ikeagwuani, Donald Chimobi Nwonu, "Emerging trends in expansive soil stabilisation: A review," Journal of Rock Mechanics and Geotechnical Engineering, vol. 11, no. 2, pp. 423-440, 2019.DOI: 10.1016/j.jrmge.2018.08.01.

[44] Mehdi Mirzababaei, Mohsen Miraftab, Mostafa Mohamed, Paul McMahon, "Impact of carpet waste fibre addition on swelling properties of compacted clays," Geotechnical and Geological Engineering, vol. 31, no. 1, pp. 173-182. 2013. DOI: $10.1007 \% 2 F s 10706-012-9578-2$.

[45] AR Estabragh, AT Bordbar, AA Javadi, "A study on the mechanical behavior of a fiber-clay composite with natural fiber," Geotechnical and Geological Engineering, vol. 31, no. 2, pp. 501-510. 2013. DOI: 10.1007/s10706-012-9602-6.

[46] Vandna Sharma, Hemant K Vinayak, Bhanu M Marwaha,"Enhancing compressive strength of soil using natural fibers," Construction and B.M, vol. 93, pp. 943-949. 2015. DOI: 10.1016/j.conbuildmat.2015.05.065.

[47] Jitendra Yadav, Shiv Kailash Tiwari, "The impact of end-of-life tires on the mechanical properties of fine-grained soil: a review. In: Env, develop and sustainab," Springer, 2017. DOI: 10.1007/s10668-017-0054-2.

[48] George Rowland Otoko, "A review of the stabilization of problematic soils," Inter Journal of Eng and Techn Research, vol. 2, no. 5, pp. 1-6. 2014.

[49] JB Croft, "The influence of soil mineralogical composition on cement stabilization,"Geotechnique. vol. 17, no. 2, pp. 119-135.1967.

[50] H Uchikawa, S Uchida, "Influence of pozzolana on the hydration of C3A," In Proceedings of the 7th Int Congress on the Chemistry of Cement, Sub-Theme IV, Paris, France, pp. 24-29, July 1980.

[51] A Kezdi,"Chemical Soil Stabilizationl, Stabilized Earth Roads Developments in Geotechnical," Engg Elsevier, vol.19, 1979. London.

[52] S.P Deng, MA Tabatabai,"Effect of tillage and residue management on enzyme activities in soils," Biology and Fertility of Soils, vol. 22, no. 3, pp. 202-207.1996.

[53] Mohamed Khemissa, Abdelkrim Mahamedi,"Cement and lime mixture stabilization of an expansive overconsolidated clay," Applied Clay Science, vol. 95, pp. 104-110, 2014. DOI: 10.1016/j.clay.2014.03.017.

[54] Dallas N Little, Syam Nair, "Recommended practice for stabilization of subgrade soils and base materials, "National cooperative highway research program. 2009.

[55] Bhaskar Chandra Srinivas Chittoori,"Clay mineralogy effects on long-term performance of chemically treated expansive clays," Doctoral dissertation, University of Texas at Arlington. 2008. https://rc.library.uta.edu/uta-ir/handle/1 0106/1809 (accessed March.18,2021).

[56] Aravind Pedarla, Srinivas Chittoori, Anand J Puppala," Influence of mineralogy and plasticity index on the stabilization effectiveness of expansive clays,"Transportation research record, vol. 2212, no. 1, pp. 91-99. 2011. DOI: 10.3141/2212-10.

[57] Xiangjun Pei, Fanyu Zhang, Wanjiong Wu, Shouyun Liang, "Physicochemical and index properties of loess stabilized with lime and fly ash piles, "Applied Clay Science, vol. 114, pp. 77-84, 2015. DOI: 10.1016/j.clay.2015.05.007.

[58] Chulmin Jung , Antonio Bobet, "Post-construction evaluation of lime-treated soils," Joint Transportation Research Program, vol.319, 2008. DOI: 10.5703/1288284313443.

[59] Dallas N Little, "Evaluation of structural properties of lime stabilized soils and aggregates," Arlington, VA: National Lime Association, vol. 1, pp. 1-89, 1999.

[60] Pranshoo Solanki, Musharraf M Zaman, Jeff Dean, "Resilient modulus of clay subgrades stabilized with lime, class C fly ash, and cement kiln dust for pavement design," Transportation research record, vol. 2186, no. 1, pp. 101-110, 2010. DOI: $10.3141 / 2186-11$

[61] Khairul Anuar Kassim, Kok Kai Chern, "Lime stabilized Malaysian cohesive soils," Malaysian Journal of Civil Engineering, vol. 16, no. 1, pp. 13-23. 2004. https://engineering.utm.my/civil/mjce/wp-content/uploads/s ites/40/2013/10/Lime-Stabilized-Malaysian-Cohesive-Soils. pdf (accessed March.18,2021).

[62] Hsai-Yang Fang,"Foundation engineering handbook," Springer Science and Business Media. 2013.

[63] B Wibawa, "Swelling Clay Stabilized with Lime," Civil Engineering Research, pp.47- 48, 2003.

[64] S Bhuvaneshwari, R Sowbi, "Stabilization of expansive soils-evaluation of the behaviour with lime," Int J Civ Eng Technol (IJCIET). Vol. 8, pp. 1003-1013, 2017.

[65] PT Sherwood,"Soil stabilization with cement and lime," TRL State of the Art Review,1993. London.

[66] Nuno Cristelo, Stephanie Glendinning, Lisete Fernandes, Amândio Teixeira Pinto, "Effects of alkaline-activated fly ash and Portland cement on soft soil stabilisation," Acta Geotechnica, vol. 8, no. 4, pp. 395-405. 2013. DOI: 10.1007\%2Fs11440-012-0200-9.

[67] Amer Ali Al-Rawas, AW Hago, Hilal Al-Sarmi,"Effect of 
lime, cement and Sarooj (artificial pozzolan) on the swelling potential of an expansive soil from Oman," Building and Environment, vol. 40, no.5, pp. 681-687. 2005. DOI: 10.1016/j.buildenv.2004.08.028.

[68] Sireesh Saride, Anand J Puppala, Srujan R Chikyala, "Swell-shrink and strength behaviors of lime and cement stabilized expansive organic clays," Applied Clay Sciencel, vol. 85, pp. 39-45, 2013. DOI: 10.1016/j.clay.2013.09.008.

[69] Yanjun Du, Shenglin Li, Shigenori Hayashi, "Swellingshrinkage properties and soil improvement of compacted expansive soil, Ning-Liang Highway, China," Engineering Geology, vol. 53, no.3-4, pp. 351-358, 1999. DOI:10.1016/S0013-7952(98)00086-6.

[70] Bidula Bose, "Effect of curing period and temperature on characteristics of stabilized expansive soil," Inter Journal of Emerging Trends in Eng and Develop. vol. 4, no. 2, pp. 704-713, 2012.

[71] Olugbenga Amu, AB Fajobi, SO Afekhuai, "Stabilizing Potential Of Cement-Fly Ash Mixture On Expansive Clay Soil," Journal of Tech and Edu in Nigeria, vol. 12, no.2, pp. 1-8. 2007. DOI: 10.4314/joten.v12i2.35698.

[72] Erdal Cokca, "Use of class C fly ashes for the stabilization of an expansive soil," Journal of Geot and Geoenviron Eng, vol. 127, no.7, pp. 568-573, 2001.

[73] NS Pandian, K Krishna, "The pozzolanic effect of fly ash on the CBR behavior of black cotton soil," Journal of testing and evaluation, vol. 31, no. 6, pp. 479-485, 2003.DOI: 10.1520/JTE12375J.

[74] Anil Misra, Debabrata Biswas, Sushant Upadhyaya, "Physico-mechanical behavior of self-cementing class C fly ash-clay mixtures," Fuel. vol.84, no.11, pp. 1410-1422. 2005. DOI: 10.1016/j.fuel.2004.10.018.

[75] Manmay Kumar Mohanty, "Stabilization of expansive soils using fly ash," Master dissertation, Depart of Civil Eng National Inst of Tech, Rourkela Odisha, India. 2015.

[76] Swae Nl Than, Thiha Zaw, "Study on Stabilization of Expansive Soil with Fly-ash," Iconic Research and Eng Journals, vol. 3, no.1, pp. 395-399, 2019.

[77] Singh Vivek, Jain Rajesh, "Effect of Cement Kiln Dust (CKD) On Engineering Properties of Black Cotton Soil," International Journal for Innovative Research in Science and Technology, vol. 1, no. 12, pp.86-90, 2015.

[78] S Vivek, Parimal Kumar, Vivek Shukla, Kiran Markal, K Mallikarjun, "Stabilization of Expansive Soils Using Construction ond Demolition Waste," International Research Journal of Eng and Tech, vol. 5, no.6, pp. 291-294, 2018.

https://www.irjet.net/archives/V5/i6/IRJET-V5I662.pdf (accessed March.18,2021).

[79] P Pujari, M Sudeep, "Stabilization of expansive soil using cement kiln dust," Imperial Journal of Interdisciplinary Research, vol. 2, no.7, pp.1089-1094. 2016.

[80] Chulmin Jung, Antonio Bobet, Nayyar Zia Siddiki, Daehyeon Kim, "Postconstruction evaluation of subgrades chemically treated with lime kiln dust," Journal of materials in civil eng, vol. 23, no. 7, pp. 931-940, 2011. DOI:10.1061/(ASCE)MT.1943-5533.0000251.
[81] Xin Kang, Louis Ge, Gi-Chun Kang, Christopher Mathews, "Laboratory investigation of the strength, stiffness, and thermal conductivity of fly ash and lime kiln dust stabilised clay subgrade materials," Road materials and pavement design, vol.16, no.4, pp. 928-945, 2015. DOI: 10.1080/14680629.2015.1028970.

[82] Anil Kumar Sharma, PV Sivapullaiah, "Improvement of strength of expansive soil with waste granulated blast furnace slag," In proceeding GeoCongress, State of the Art and Practice in Geotech Eng, pp. 3920-3928. 2012. DOI: 10.1061/9780784412121.402.

[83] Vanesa Ortega-López, Juan M Manso, II Cuesta, Javier J González, "The long-term accelerated expansion of various ladle-furnace basic slags and their soil-stabilization applications," Construction and B.M, vol. 68, pp. 455-464, 2014. DOI:10.1016/j.conbuildmat.2014.07.023.

[84] Juan M Manso, Vanessa Ortega-López, Juan A Polanco, Jesus Setién, "The use of ladle furnace slag in soil stabilization," Construction and B.M, vol. 40, pp. 126-134, 2013. DOI: 10.1016/j.conbuildmat.2012.09.079.

[85] Laxmikant Yadu, RK Tripathi, "Effects of granulated blast furnace slag in the engineering behaviour of stabilized soft soil," Procedia Eng, vol. 51, pp. 125-131, 2013. DOI:10.1016/j.proeng.2013.01.019.

[86] CR Devi, S Surendhar, P Vijaya Kumar, M Sivaraja, "Bottom Ash as an Additive Material for Stabilization of Expansive Soil," Int. J. Eng. Tech, vol. 4, no. 2, pp. 174-180, 2018.

[87] Yilmaz Işık, Berrin Civelekoglu, "Gypsum: An additive for stabilization of swelling clay soils, "Applied Clay Science, vol. 44, no. 1-2, pp. 166-172, 2009. DOI: 10.1016/j.clay.2009.01.020.

[88] Ekrem Kalkan, "Effects of waste material-lime additive mixtures on mechanical properties of granular soils, "Bulletin of Eng Geol and the Env, vol. 71, no. 1, pp. 99-103, 2012. DOI: 10.1007/s10064-011-0409-0.

[89] Negi Chhaya, RK Yadav, AK Singhai, "Effect of Silica Fume on Engineering Properties of Black Cotton Soil," International Journal of Scientific and Eng Research, vol. 4, no. 8, pp. 828-832, 2012.

[90] K Aswani Chandh, S Akhila, "A Review on Strength Improvement of Expansive Soils by Bituminous Admixtures," VFSTR Journal of STEM, vol. 3, no. 1, pp. 2455-2062, 2017. https://vignan.ac.in/vfstrstem/vol3/Aswa ni\%20Chandh.pdf (accessed March.18,2021).

[91] Yonfu Xu, Babak Jamhiri, Shazim Ali Memon,"On the recent trends in expansive soil stabilization using calcium-based stabilizer materials: A comprehensive review," Advances in Materials Science and Eng, 2020. DOI: 10.1155/2020/1510969.

[92] Thomas M Petry, J Clyde Armstrong, "Stabilization of expansive clay soils,"Transportation Research Record, vol.1219, 1989

[93] Umair Hasan, Amin Chegenizadeh, Mochamad Arief Budihardjo, Hamid Nikraz, "A review of the stabilisation techniques on expansive soils," Australian Journal of Basic and Applied Sciences, vol. 9, no. 7, pp. 541-548, 2015. 
http://ajbasweb.com/.../541-548.pdf (accessed March.18, 2021).

[94] Sudipta Ghosh, Somnath Mukherjee, Kunal Sarkar, Ashraf Z Al-Hamdan, Krishna Reddy,"Experimental study on chromium containment by admixed soil liner,"Journal of Env Eng, vol. 138, no.10, pp. 1048-1057, 2012. DOI: 10.1061/(ASCE)EE.1943-7870.0000563.

[95] Isaac I Akinwumi, Oluwapelumi O Ojuri, Daniel Edem, Adebanji Ogbiye, "Sawdust stabilization of lateritic clay as a landfill liner to retain heavy metals," In Geo-chicago, pp. 478-487, 2016. DOI: 10.1061/9780784480144.047.

[96] RK Etim, AO Eberemu, KJ Osinubi, "Stabilization of black cotton soil with lime and iron ore tailings admixture," Transportation Geotechnics, vol. 10, pp. 85-95, 2017. DOI: 10.1016/j.trgeo.2017.01.002.

[97] American Coal Ash Association, "Soil stabilization and pavement recycling with self cementing coal fly ash," 2008. Aurora, USA.

[98] ASTM, "Standard practice for the design of stabilization of soils and soillike materials with self-cementing fly ash," D 7762, American Society for Testing and Materials, PA, USA, 2011. USA.

[99] Zach Thomas, Dale Harrington, David J White," Fly Ash Soil Stabilization for Non-Uniform Subgrade Soils," Eng Properties and Construction Guidelines (No. IHRB Project
TR-461), Iowa State University, 2005.

[100] David J White, Pavana KR Vennapusa, Peter Becker, Christianna White, Boone county, "Fly ash stabilization of subgrade," Iowa Department Transportation, 2013.

[101] Armand Augustin Fondjo, Elizabeth Theron, Richard P Ray, "Semi-Empirical Model for Predicting the Swelling Stress of Compacted, Unsaturated Expansive Soils," Civil Engineering and Architecture, Vol. 9, No. 1, pp. 225-239, 2021. DOI:10.13189/cea.2021.090119.

[102] Armand Augustin Fondjo, Elizabeth Theron, "Application of Mathematical Function to Estimate the Compaction Characteristics of Unsaturated Soils," Civil Engineering and Architecture, Vol. 9, No.1, pp. 255-262, 2021. DOI:10.13189/cea.2021.090121.

[103] Armand Augustin Fondjo, Thywill Cephas Dzogbewu, "Swelling Stress and Suction Correlation of Compacted, Heaving Soils ," Civil Engineering and Architecture, Vol. 8, No.4, pp. 721-733, 2020. DOI: 10.13189/cea.2020.080434.

[104] Armand Augustin Fondjo, Elizabeth Theron, Richard P Ray, "Models for Predicting the Suction of Heaving Compacted Soils Using Geotechnical Properties," Proc. 14th Baltic Sea Region Geotechnical Conference 2021 Helsinki, Finlande, 18-19 January. IOP Conference Series: Earth and Environmental Science,Vol.727, 2021. DOI: 10.1088/1755-1315/727/1/012016. 